\title{
OS SENTIDOS NO ENSINO DE HISTÓRIA
}

\author{
THE SENSES IN THE TEACHING OF HISTORY
}

Aline Machado Krause

Gabriel Vinicius Vieira ${ }^{1}$

\begin{abstract}
RESUMO: Este artigo consiste na exposição da aplicação prática da proposta de trabalhar temas históricos na sala de aula utilizando os sentidos como técnica principal para evocação da curiosidade e do conhecimento, mas sem reduzir essa mesma curiosidade e esse mesmo conhecimento apenas aos sentidos. Tendo como influências teóricas os pensamentos sobre escolas de Illich, sobre oficinas de Corrêa, sobre micro-história de Ginzburg e sobre história cultural de Peter Burke, temos como objetivo uma aula em que os alunos participem não só através das perguntas do professor, mas também do próprio desenvolvimento dos temas, e que materializa o conhecimento sobre sociedades antigas, da vida de pessoas que morreram há milênios, lembrando da importância destes temas para a nossa sociedade e da importância tanto da vida individual e social como das estruturas políticas, econômicas, culturais e sociais. Assim, pretendemos uma aula divertida, interessante, engraçada, mas sem esquecer-se da história e sem subestimar o conhecimento das crianças.
\end{abstract}

Palavras-chave: Sentidos. Ensino de História. Interação; crianças.

\begin{abstract}
This article is an exposition of the practical application of the propose of working historical themes in the classroom using the senses as the main technique for evoking the curiosity and knowledge, but without reducing that same curiosity and knowledge only to the senses. Having as theoretical influences Illich's teories about schools, Correa's workshops, Ginzburg's micro-history and Peter Burke's cultural history, our goal is a class in which students participate not only through the teacher's questions, but also in the very development of themes, and which materializes the knowledge about ancient societies, the lives of people who died millenniums ago, without forgetting the importance of the historical themes for our society and the importance of both individual life and the political, economic, cultural and social estructures of society. Therefore, we want a fun, interesting, funny class without forgetting the history and without underestimating the knowledge of children.
\end{abstract}

Keywords: Senses. History Teaching. Interaction. Children

\footnotetext{
${ }^{1}$ Universidade Federal de Santa Maria.
} 


\section{Introdução}

As atividades de ensino de História que apresentaremos aqui surgiram devido ao forte interesse dos envolvidos, todos ligados ao curso de História - Licenciatura e Bacharelado da Universidade Federal de Santa Maria, em realizar pesquisas e experiências de ensino inovadoras e que se diferenciassem da estrutura tradicional do curso. Partimos, então, em busca de algo realmente inédito no ensino de História e foi no cruzamento de textos e referências com as quais trabalhávamos e de nossos pensamentos e idéias sobre como deveria ser o ensino de História que montamos nossa proposta.

O ramo de influências mais diretamente relacionado com o ensino foi sendo desenvolvido durante nossas experiências e discussões acadêmicas. Entramos em contato com "Sociedade Sem Escolas" (ILLICH, 1971), um livro sobre o qual discutimos e conversamos muito; e com as considerações sobre as ações dos professores no sistema escolar e sobre oficinas, de Guilherme Corrêa (CORRÊA, 2000).

As questões propostas por Corrêa certamente foram as que mais nos influenciaram no sentido da prática do professor, especialmente devido à discussão sobre um de seus textos que tivemos a oportunidade de ter com ele. O ponto principal que levamos dessas discussões foi a interação entre alunos e professores e a necessidade da quebra de hierarquias para uma verdadeira troca de conhecimentos.

Além disso, o diálogo que se estabelece em torno do temaeixo de cada oficina, suscitado à medida em que ativa a expressão dos participantes (tanto por evocar suas experiências, quanto por levantar dúvidas, expectativas e 'sacações'), é resultado da quebra de hierarquias (possível somente se se esvazia o sentido da relação professor-aluno, ou seja, se não há mais lugar fixo para aquele que sabe, que só faz ensinar para os que, também fixos, não sabem, e que só fazem aprender). Busca-se ainda, na oficina, a quebra de um outro tipo de hierarquia que não a burocrática - que distribui as pessoas em funções fixas, em decorrência de cargos que assumem, de bens que acumulam ou de diplomas que detém - mas sim uma hierarquia do conhecimento. Tal 
hierarquia é corolária da hierarquia do tipo burocrático e se dá, muitas vezes, pela dentenção de um discurso especializado que justifica a maior importância de quem o profere em relação aos outros (CORRÊA, 2000, p.121-122).

Com relação ao ensino de História, mais especificamente, nossos principais referenciais foram as discussões propostas por Cainelli (2004; 2006), principalmente suas discussões sobre o trabalho no ensino fundamental, nosso foco.

Um segundo ramo de influências é a nossa área de pesquisas em história, a História Cultural. Nossas pesquisas concentram-se em memória, identidade, patrimônio e cultura. Peter Burke, em "O que é História Cultural?", nos coloca:

\begin{abstract}
O interesse crescente pela história dos sentidos corre paralelo ao interesse pelas emoções. Há uma tradição de estudos sobre a visão (...), bem como trabalhos sobre o olhar, inspirados em Foucault. Foram feitas referências ocasionais ao som do passado por Johan Huizinga e Gilberto Freyre (...). Hoje, no entanto, encontramos tentativas ambiciosas de escrever sobre todos os sentidos em detalhes (BURKE, 2008, p. 143-144).
\end{abstract}

Foi a partir da leitura desse capítulo que surgiu o ponto central de nosso trabalho: os sentidos. Assim, em busca de uma ação inédita, relacionamos nossas idéias sobre o ensino com nossos conhecimentos sobre a História, de forma geral, e a história cultural e dos sentidos, mais especificamente.

Definimos, então, nossa proposta: trabalhar temas históricos utilizando os sentidos como técnica principal para evocação da curiosidade e do conhecimento, mas sem reduzir essa mesma curiosidade e esse mesmo conhecimento apenas aos sentidos.

\title{
Objetivos
}

Após a definição de nossa proposta, estabelecemos alguns objetivos, que abordam tanto a metodologia como as técnicas que utilizaríamos. 0 
primeiro objetivo era buscar uma maior interação com os alunos, em comparação com aulas expositivas tradicionais e tendo como base o modelo de oficina proposto por Corrêa. Como será discutido posteriormente, tivemos que fazer adaptações, pois acabamos realizando as atividades dentro de uma sala de aula. Mesmo assim, buscamos sempre incentivar a participação das crianças, não apenas a responderem nossas perguntas, mas também para que trouxessem seus conhecimentos para a discussão. Ainda, a interação também foi buscada através da participação das crianças na criação das sensações (fazendo um barulho, produzindo uma imagem, trabalhando o tato, entre outros). Assim, buscamos a interação nas mais diversas formas, da interação de conhecimentos à interação na produção e no protagonismo da aula.

Foto 1: atividade sobre Roma, trabalhando o Senado e a influência grega.

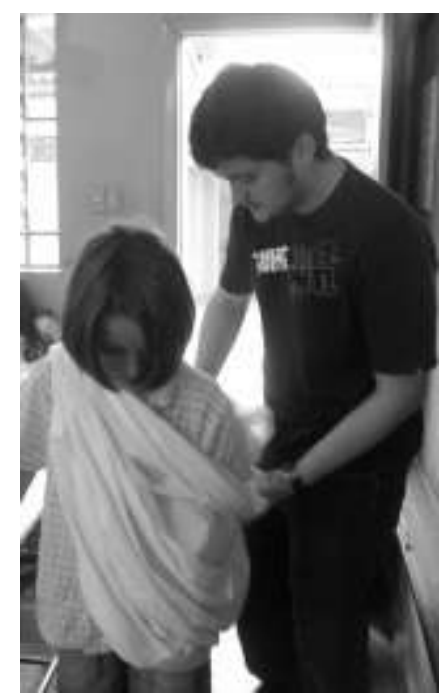

O segundo objetivo é a materialização de um conhecimento sobre sociedades que existiram há milênios. Escolhemos trabalhar com os sentidos não apenas pelo ineditismo da ação (de acordo com nossos conhecimentos), mas também porque proporciona um conhecimento material, visível, audível, tactível, degustativo e sonoro. Nosso objetivo era, portanto, transformar um conhecimento abstrato sobre uma cultura que 
viveu há muito tempo em um conhecimento perceptível. Por exemplo, em vez de simplesmente falarmos que a pesca era a principal atividade econômica, discutimos isso mostrando peixes e seu cheiro forte.

Foto 2: atividade sobre Reinos Africanos, passando areia para os alunos tocarem

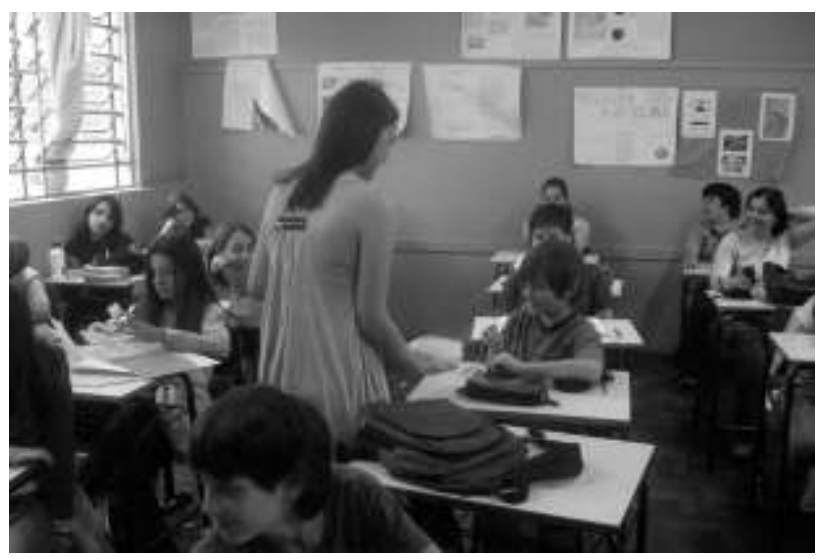

O terceiro objetivo, relacionado diretamente com o segundo, era a "atualização" do conhecimento, ou seja, a colocação de questões relevantes atualmente a partir da discussão dos temas históricos. Não bastava, para nós, materializar a vida de sociedades antigas a partir dos sentidos; também era necessário que esse conhecimento fosse importante, relevante para a vida das crianças. Assim, não falávamos apenas em cidadania grega, mas também da cidadania atual; não apenas na situação das mulheres romanas, mas também da situação atual das mulheres. Essa questão era fundamental, em nossa opinião, para que as crianças percebessem aquelas sociedades distantes como culturas que foram vivas, que eram compostas por pessoas, e não apenas como informações no quadro; era fundamental, também, para a percepção de que a história é formada por diversos processos, por continuidades e descontinuidades.

Por fim, nosso quarto objetivo era não esquecer das estruturas históricas. A partir da utilização dos sentidos, trabalharíamos a percepção individual, a vida de pessoas comuns. Nossas concepções teóricas de história (LIMA, 2006), no entanto, ao mesmo tempo em que nos levam a 
introduzir temas próximos à vida individual de pessoas comuns, também consideram importante o trabalho de estruturas políticas, econômicas, sociais e culturais. No entanto, a questão não era apenas trabalhar os dois aspectos, mas trabalhar de maneira a relacioná-los, a mostrar que um não existe sem o outro, de forma que são as pessoas, em suas relações sociais, que "criam" as estruturas, ao mesmo tempo em que essas estruturas, de maneira circular, também influenciam a vida das pessoas, tanto no aspecto público quanto privado.

\section{Escola}

Pelo caráter da nossa proposta, pensamos que teríamos uma aceitação maior entre crianças do que entre adolescentes e adultos e, assim, entramos em contato com a Escola Estadual de Ensino Fundamental General Edson Figueiredo para conversamos com uma turma de alunos. Primeiramente, falamos com a vice-diretora da escola, que prontamente nos encaminhou até a professora de História das quintas séries, Nara; apresentamos a nossa proposta, que despertou o seu interesse e fomos, então, falar com uma das turmas de quinta série.

Com a conversa, foram definidos os seguintes pontos: as atividades não seriam realizadas em formato de oficina, no turno inverso, pois diversos alunos que se interessaram em participar dependiam do transporte escolar, ficando assim definido que faríamos uma espécie de intervenção no período de aula destinado à História; os temas trabalhados seriam os que os alunos estudaram durante o ano, Grécia, Reinos Africanos, Roma e Cristianismo (caso a professora conseguisse chegar a esse último conteúdo); por fim, fomos indagados pela professora sobre a possibilidade de realizarmos as atividades com uma segunda turma, pois ela tinha aula de História no mesmo dia da turma que já havíamos conversado e os alunos demonstraram interesse na proposta.

Assim, após as conversas, ficaram estabelecidas algumas restrições:

o tempo que teríamos seria, no máximo, o de um período de aula (50 
minutos); por utilizarmos o espaço da escola, deveríamos seguir as regras da mesma, como, por exemplo, não dar alimentos sólidos e não tirar fotos em que os rostos das crianças aparecessem. Também acertamos com a professora que antes da realização da atividade na sexta-feira sempre iríamos à escola na quarta-feira para expor a nossa proposta, embora nada do que apresentamos tenha sido censurado. Com a primeira turma, as atividades ocorreriam na segunda hora-aula do turno da tarde (das $14 \mathrm{~h} 05 \mathrm{~min}$ às $14 \mathrm{~h} 55 \mathrm{~min})$, com o segundo grupo a intervenção era na quarta hora-aula (16h às $16 \mathrm{~h} 50 \mathrm{~min})$.

Desde o início das atividades fomos muito bem recepcionados pela escola, especialmente pela Prof. ${ }^{a}$ Nara, pela direção e pelos alunos da quinta série; dessa forma, fizemo-nos presentes junto à comunidade escolar participando de eventos como a mostra de trabalhos pedagógicos e as comemorações pelo aniversário da escola. O envolvimento das turmas com a nossa proposta também foi muito satisfatório, inclusive com o fim das atividades muitos alunos nos indagaram sobre a possibilidade de uma continuação das atividades no próximo ano letivo.

\section{Atividades}

Realizamos a primeira atividade em 15 de outubro de 2010, com a temática: Atenas e Esparta, formação e período arcaico. Para a visão, usamos um lençol vermelho e outro branco como se fossem mantos, a partir disso, trabalhamos a mitologia e a cultura grega através das cores do deus protetor de cada pólis, sendo o branco para Palas Atenas, protetora de Atenas, e o vermelho para Ares, protetor de Esparta; também foram abordadas pela visão a posição da mulher na sociedade espartana e na sociedade ateniense, principalmente as diferenças entre a situação da mulher entre Atenas e Esparta e os dias de hoje (o que gerou uma discussão sobre o papel da mulher e do homem da sociedade que nos surpreendeu pela diversidade de posições dos alunos com relação ao assunto), e as obras de Homero, Ilíada e Odisséia, trabalhadas não apenas 
como fontes para o período homérico, mas também como principais influências da cultura grega dos períodos arcaico e clássico.

A partir da audição, com o burburinho em Atenas e os gritos de guerra em Esparta (pedimos para que os alunos os emitissem, primeiramente conversando e depois gritando "Brasil" três vezes), falamos sobre a educação em Atenas, realizada em praças através de discussões políticas e filosóficas, e sobre a educação militar espartana, objetivando a formação de soldados e a disciplina (que relacionamos com a disciplina de gritar "Brasil"). As transições políticas (monarquia, aristocracia, ditadura, democracia) e as divisões sociais (quem poderia ser cidadão, quem era escravo, etc.) também foram abordadas a partir da audição, do burburinho de muitas pessoas conversando ao mesmo tempo e de discussão entre duas pessoas. Além disso, a partir desse assunto, abordamos a democracia atual e sua diferença em relação à democracia grega. Perguntamos se as pessoas discutem política nas praças, se nossa democracia é direta, o que significa a democracia ser representativa, se a participação das pessoas na democracia era só o voto, o que significava ser cidadão em Atenas, em Esparta e atualmente, entre outros.

Foto 3: atividade sobre Grécia, trabalhando Homero e mitologia.

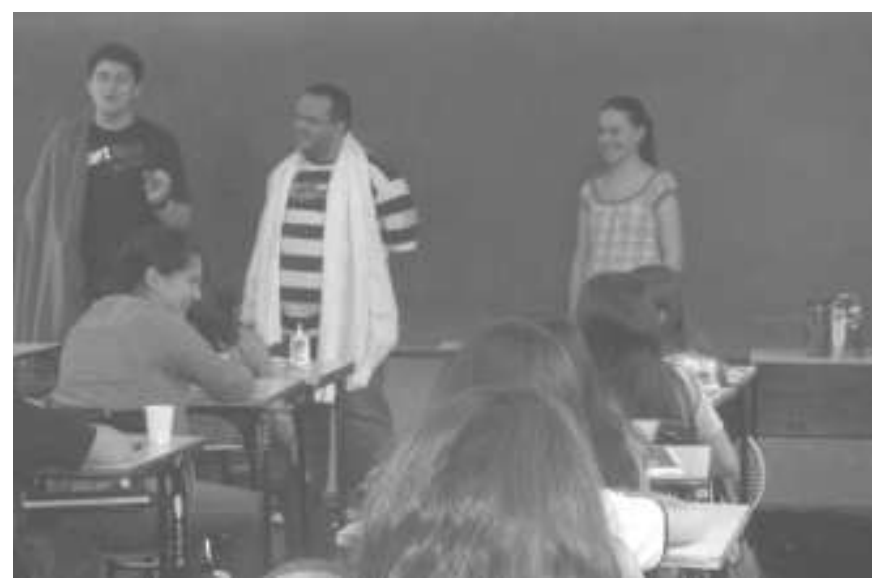

No olfato, abordamos a partir do cheiro de suor (invocado pela memória) a educação espartana e a partir da sardinha a situação de Atenas 
como cidade portuária. Associado a isso, trabalhamos o tato, abordando através do vento (obtido por um ventilador) o comércio ateniense (que em sua maioria era feito pelo mar, com barcos a vela) e a evocação de dor e cansaço para a educação espartana, que era baseada em exercícios físicos.

Com o paladar, trabalhamos a economia e as ditaduras atenienses, através da azeitona e de suco de uva, representando vinho, pois Sólon, um dos ditadores, foi quem incentivou o cultivo da oliveira e da videira em substituição ao de cereais, promovendo uma grande reforma econômica.

Foto 4: atividade sobre Grécia, alguns dos materiais usados para evocar os sentidos

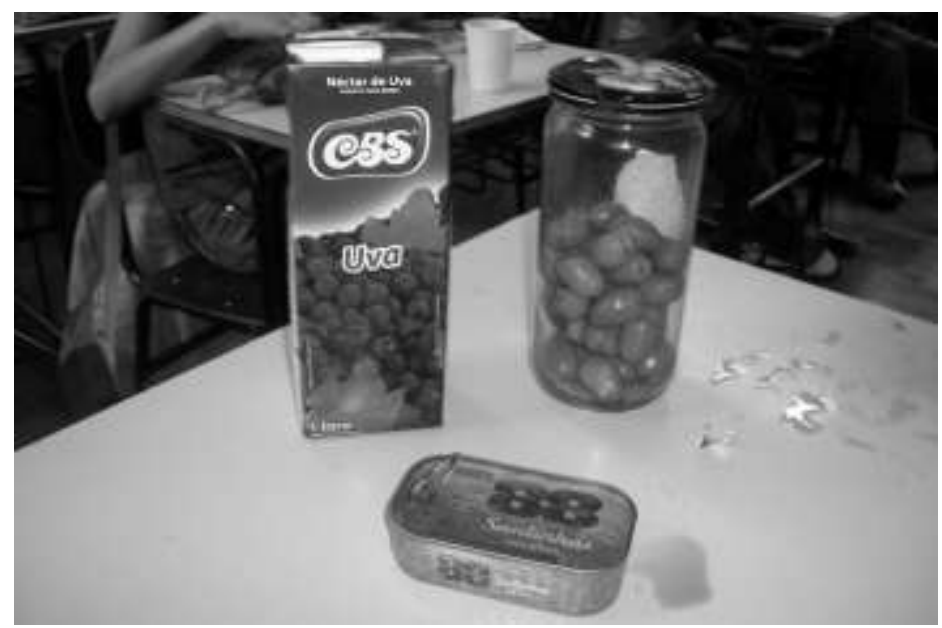

$\mathrm{Na}$ execução dessa primeira atividade percebemos que os alunos de ambas as turmas tinham, de modo geral, bastante interesse na história da Grécia, o que de certa forma nos surpreendeu dada a capacidade de abstração necessária para materializar um conhecimento localizado há milênios do presente. Notamos, a partir disso, o cuidado que o uso de mídias como o cinema e a internet deve dispensar não apenas quando utilizadas em sala de aula como recursos didáticos e sob a "supervisão" do professor (KORNIS, 1992); muitos alunos já haviam assistido a filmes clássicos, como "Spartacus", e recentes, como "300", outros sabiam os nomes de vários dos deuses do Olimpo e algumas lendas envolvendo semideuses e monstros, mas não conheciam a definição de "mito" e nem o (re)significado do termo "representação". Para abordamos a questão do 
mito, utilizamos o texto "Mito e Realidade" (ELIADE, 2006), enfatizando a importância de discernir entre um mito e um fato histórico e percebendo que o filme é uma forma de mostrar a realidade ou parte dela a partir de pontos de vista, e que, portanto, deve ser analisado criticamente.

A segunda atividade, realizada em 29 de outubro de 2010, foi sobre os reinos africanos no período pré-colonial. A intervenção consistiu, basicamente, em abordar as diferenças entre os reinos islâmicos do litoral norte da África e os reinos animistas subsaarianos. No mesmo período, os alunos estavam fazendo trabalhos bastante detalhados sobre os reinos africanos (embora muitos não haviam começado até o dia da atividade). As turmas foram divididas em grupos que deveriam pesquisar e representar aspectos culturais bem específicos, como, por exemplo, a arquitetura islâmica ou as máscaras animistas. Segundo a professora titular, a ideia de trabalhar os reinos africanos veio da visibilidade que o continente africano teve no ano de 2010 através da mídia, devido à Copa do Mundo de Futebol (FIFA), ocorrido na África do Sul. Dessa forma, como havíamos combinado com as turmas de que os temas abordados pela nossa proposta seriam os mesmos trabalhados em sala de aula pela professora titular, sugerimos e os alunos aceitaram que os reinos africanos fossem trabalhados através dos sentidos. Além disso, é interessante notar como a atitude da professora entra em acordo com a lei no 10.639/2003, que instituiu a obrigatoriedade do ensino de história e cultura afro-brasileira e africana na educação básica.

Foto 5: atividade sobre Reinos Africanos, trabalhando as religiões.

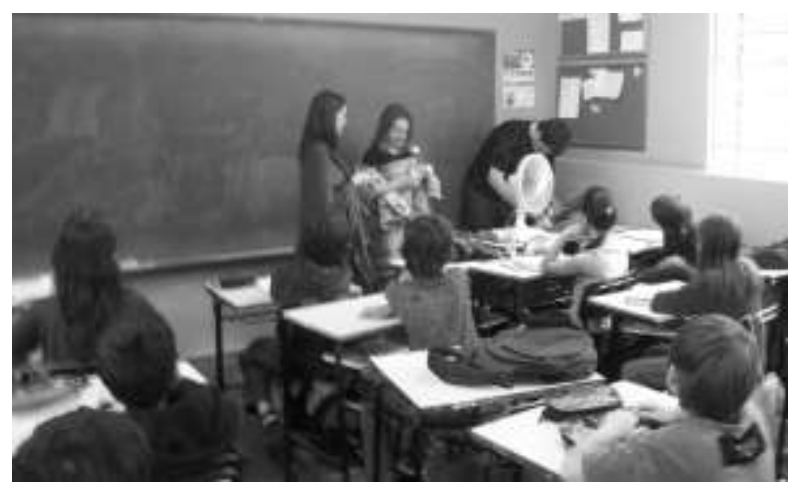


Como base para nossas atividades sobre reinos africanos, utilizamos os textos "Reconhecendo ou construindo uma polaridade étnico-identitária? Desafios do ensino de história no imediato contexto pós-Lei no 10.639" (PEREIRA, 2008) e "Em torno das 'Diretrizes curriculares nacionais para a educação das relações étnico-raciais e para o ensino de história e cultura afro-brasileira e africana': uma conversa com historiadores" (Abreu e Mattos, 2008), além de alguns capítulos da recém lançada "História Geral da África" (KI-ZERBO, 2010).

Para a visão, utilizamos um lençol escuro para demonstrar as roupas islâmicas e diversas toalhas coloridas formando uma única peça para demonstrar as vestes características dos reinos animistas. Posteriormente, instigamos as crianças a falar sobre o que sabiam sobre as ambas as culturas; a cultura islâmica era a que tinham mais informações a respeito, especialmente sobre a religião. Na segunda turma, uma aluna, neta de islâmicos, narrou como as orações são proferidas nas cinco vezes durante o dia; a partir disso, a religião também foi trabalhada pela audição, através das rezas islâmicas e do batuque de um tambor (tocado pelos próprios alunos) para as cerimônias de povos animistas.

Foto 6: atividade sobre Reinos Africanos, trabalhando a cultura através dos sons dos tambores

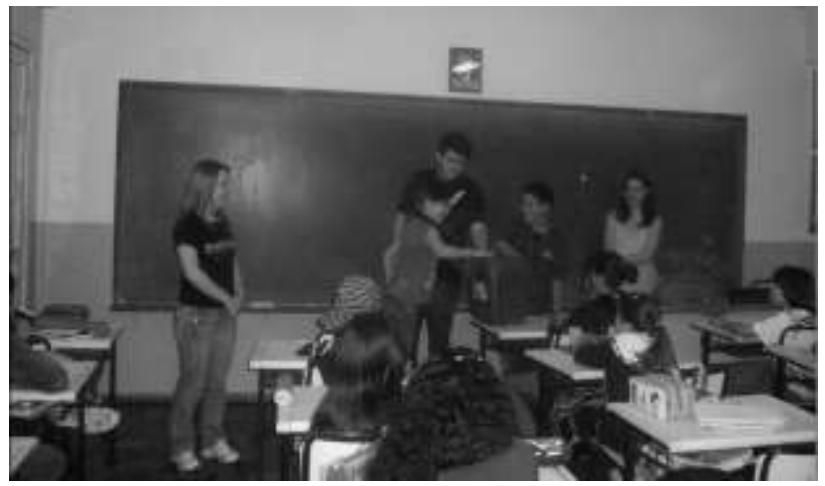

Para o paladar, trabalhamos a economia islâmica através de cereais (como trigo e cevada), pois o solo do litoral norte do continente é mais propício para esse tipo de cultivo; já para os reinos animistas trabalhamos com carne crua, pois a abundante fauna da região fornecia uma 
alimentação rica em proteínas. Para o olfato, trabalhamos o cheiro de livro velho para mostrar o avanço científico dos reinos islâmicos, fazendo referência à Biblioteca da Alexandria e sua importância para o avanço da humanidade até hoje sem estimativas e o cheiro de grama para mostrar que os povos dos reinos animistas viviam em grande contato com a natureza.

Foto 7: atividade sobre Reinos Africanos, trabalhando a economia a partir da carne crua

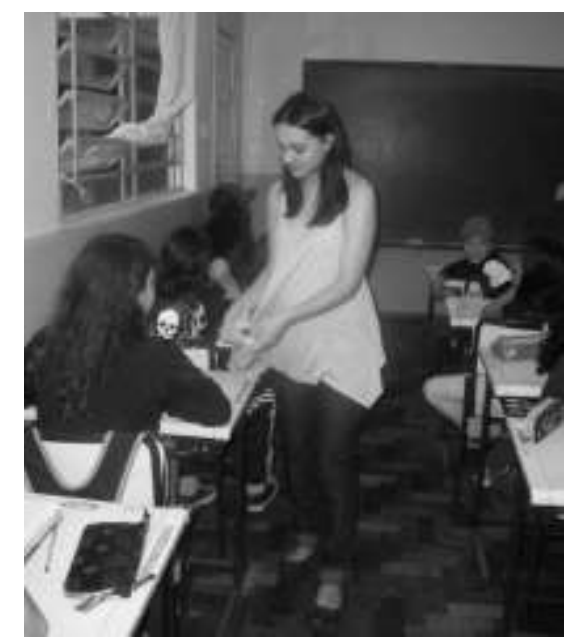

Para o tato, utilizamos a areia para trabalhar a situação dos povos islâmicos ao viverem cercados por ela no litoral e no deserto do Saara, e também a sensação de correr numa floresta, utilizando um ventilador e galhos batendo no corpo, no caso dos reinos animistas. Por fim, utilizamos fósforos para produzir fogo e trabalhar a importância deste nas sociedades animistas. Falamos sobre o fato de esses povos manterem o fogo sempre aceso dentro das casas feitas de barro e sem janelas, questionamos as crianças sobre isso e algumas acertaram ao falar sobre o aquecimento em dias de chuva e a solidificação do barro, relacionando ao processo de fabricação de tijolos nas olarias; a partir disso apresentamos também o sentido religioso, falando sobre a representação dos antepassados através do fogo e o sentido de mantê-lo sempre aceso para que a memória destes não seja esquecida (SLENES, 1999). 
Por este não ser um tema que as crianças têm muito contato, pensamos que não levaríamos mais do que 30mim para realizar essa intervenção e acabamos utilizando os 50 minutos de que dispúnhamos. A curiosidade e o envolvimento dos alunos de certa forma nos surpreenderam, mas acreditamos que os seus trabalhos sobre reinos africanos eram bem específicos e que a nossa proposta trouxe uma abordagem mais ampla de que careciam. A maioria dos alunos que já havia começado a sua pesquisa, não tinha a menor idéia do tema da pesquisa dos outros grupos; dessa forma, enfatizamos a importância de que antes de se propor uma pesquisa desse tipo, o professor realize uma introdução ao tema e justifique a divisão dos temas entre os grupos.

A terceira atividade foi realizada no dia 19 de novembro de 2010 e teve como temática: Monarquia e República Romanas (menos a crise e a transição para o Império). Como as duas turmas não tiveram nenhuma aula sobre Roma até a nossa intervenção, iniciamos a atividade utilizando um mapa mundi para mostrar a localização de Roma e a extensão do Império Romano.

Para a visão, utilizamos o mesmo lençol branco que levamos na atividade sobre a Grécia para mostrar a influência grega sobre a cultura romana e o Senado e seu poder durante a República; pedimos para que uma das crianças coloca-se o pano sobre um dos ombros (na transversal), da mesma maneira que os senadores romanos usavam. Também utilizamos uma arma de plástico para mostrar a ação do gládio romano e a sua importância na expansão territorial romana durante a República. Para o paladar, utilizamos o leite para contar a lenda de Rômulo e Remo da criação de Roma (em que eles teriam sido alimentados por uma loba).

Para o olfato, utilizamos a uva para trabalhar a economia e a divisão de classes a partir do vinho, enfatizando que a bebida feita a partir da uva era consumida em todas as camadas da sociedade, o que variava era a sua qualidade; enquanto os nobres e ricos bebiam um bom vinho, as camadas populares consumiam algo mais parecido com um suco de uva. 
Foto 8: atividade sobre Roma, alguns dos materiais usados.

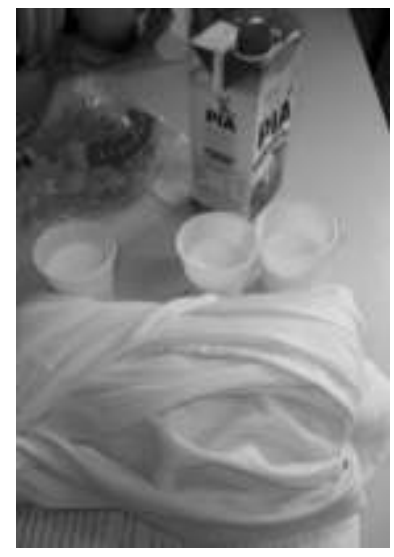

Para a audição, juntamente com o gládio, evocamos a memória sobre jogos de futebol e comparamos com os jogos de gladiadores, tanto com relação ao formato do estádio, ao barulho da torcida e a função social. Para o tato, pedimos que cinco crianças caminhassem umas em direção às outras para que se chocassem, dando a sensação de multidão, além de evocarmos a situação de haver, em vez de 30, 80 crianças dentro da sala de aula, trabalhando assim as dimensões continentais de Roma, o fato de que a cidade foi a primeira a atingir um milhão de habitantes e a situação de sua população pobre.

Por fim, cabe destacar que sempre que evocamos alguma memória ou utilizamos algo para trabalhar os sentidos, procuramos fazer os alunos participarem com perguntas diversas (gostam de azeitonas? Quem é cidadão hoje em dia? Já tomaram vinho? Já ouviram um islâmico rezar? Acham que é parecido com um cristão?) e chamá-los para frente da sala para ajudar na demonstração dos sentidos.

\section{Considerações finais}

Com esse trabalho, fomos surpreendidos diversas vezes, e todas de maneira positiva. O interesse da maioria dos alunos, a atenção com que nos escutavam e a vontade com que participavam era quase palpável. As informações e o conhecimento que traziam também eram surpreendentes em alguns momentos. Alguns alunos comentaram que haviam assistido e 
gostado de "Spartacus", um filme clássico de 1960 com 3 horas de duração, algo que nunca imaginamos que crianças gostariam. Surpreendemo-nos também com alguns comentários feitos pelos alunos sobre temas que abordamos, como democracia, cidadania, mulheres, entre outros.

Com relação aos objetivos, acreditamos tê-los alcançado. Sobre a interação, ela foi muito maior do que esperávamos, fazendo com que nosso planejamento do tempo das aulas não funcionasse (como já mencionado). Sempre que evocamos algum sentido, fizemos questão de que os sentidos de todos fossem evocados, por exemplo, ao passar as azeitonas e a carne para todos os alunos. Talvez a única situação em que não fizemos isso foi no trabalho com o tato na atividade sobre Roma. Outro ponto que nos faz avaliar a interação como bem sucedida é que, quando solicitamos a participação de algum aluno na frente da classe, tivemos que escolher entre os muitos que nos pediam para participar, portanto nunca obrigamos ninguém a interagir. Ainda, sempre que iniciamos um trabalho com um sentido ou com um tema que pudesse ser relacionado à sociedade atual, perguntamos "o que acham?", "conseguem imaginar?", "já fizeram isso?", "já sentiram isso?", buscando abrir espaço para que os alunos pudessem contribuir com seu conhecimento e suas experiências.

Sobre o objetivo da materialização, tivemos poucas formas de avaliar de maneira mais objetiva nosso sucesso. No entanto, percebemos que várias vezes as crianças faziam comentários e perguntas que demonstravam que a materialização através dos sentidos Ihes ajudava a compreender as sociedades que abordamos. A professora, logo após nossa atividade de Grécia, fez uma prova em que incluiu algumas questões abordadas por nós e as respostas da maioria dos alunos foram muito boas.

A "atualização" do conhecimento também foi alcançada de maneira satisfatória. As discussões sobre temas relacionados à sociedade em estudo e à sociedade atual costumavam tomar boa parte da aula, também influenciando na questão do tempo. As crianças se mostraram realmente interessadas em discutir temas como democracia, cidadania, república, a situação das mulheres, preconceito, escravidão, religião, entre vários outros. A questão mais importante dessas discussões, no entanto, não é a 
quantidade, a qualidade ou a variedade, mas sim que, na maioria delas, os alunos expunham pontos de vista diferentes e a discussão acontecia entre eles, sendo a nossa participação mais como incentivadores e provocadores do que como protagonistas. O ponto da História como processo com continuidades e descontinuidades também parece ter sido compreendido, embora novamente não tenhamos uma avaliação objetiva, mas um comentário de um aluno sobre como a democracia, mesmo depois de ter "sumido por muito tempo" (sic), voltou de novo, mas "um pouco diferente" (sic) porque não eram "feitas pelas mesmas pessoas" (sic), talvez sirva como indicação.

Para o quarto objetivo, novamente sofremos com a falta de uma avaliação objetiva para afirmarmos que os alunos realmente compreenderam a relação micro-macro que tentávamos trabalhar. Recorremos novamente à prova sobre Grécia que a professora aplicou e aos comentários da mesma, em que os alunos pareciam ter essa compreensão. Além disso, também voltamos aos comentários das crianças durante as atividades, como na questão dos plebeus romanos, em que pessoas pobres teriam mudado a estrutura política de Roma, de acordo com um aluno.

Além do que acreditamos ter sido bem sucedido também tivemos alguns problemas. Os principais foram as limitações impostas pela situação dos alunos e da escola, já comentadas. O problema que mais motivou conversas entre nós foi que os alunos mais velhos, que estavam repetindo a quinta série, não mostravam interesse em participar, algumas vezes se recusando a cheirar ou tocar algo que passávamos. Mesmo assim, eles prestavam atenção enquanto falávamos e não fizeram nada considerado como problema pelo ensino expositivo tradicional (como conversas laterais, falta de atenção etc.). Isso nos suscitou uma pergunta: se eles pareciam interessados, se prestavam atenção, por que se recusavam a participar?

Diversas possibilidades foram cogitadas, entre elas a de que a técnica de trabalhar com os sentidos não atrai crianças mais velhas e adolescentes, de que não participavam porque, por serem mais velhos, queriam mostrar poder ou impor respeito com relação às crianças mais novas, de que sentiam vergonha de participar por serem mais velhos e estarem repetindo 
uma série, entre outras. De fato, essas são apenas hipóteses, pois não tivemos oportunidades de testar alguma delas ou de conversar em separado com esses alunos. Acreditamos que, com a nossa intenção de realizar novamente atividades baseadas nos sentidos, mas agora não como intervenção e sim como uma aula, essa questão talvez possa ser esclarecida.

Ainda, é interessante notar como a relação entre nós e as crianças foi recíproca em alguns sentidos. Ao mesmo tempo que nos surpreendemos com elas, percebemos que algumas atitudes e comentários nossos também os surpreendiam. Notamos isso quando pedimos a eles para conversarem, na atividade de Grécia, e eles ficaram surpresos, em silêncio, sendo necessário insistirmos. Essa situação foi exemplar para nós, pois demonstrou o estranhamento e a dificuldade das crianças em fazerem algo que normalmente é recriminado pelos professores. Outra situação que surpreendeu os alunos foi o fogo na atividade dos Reinos Africanos, desta vez com expressões de surpresa em vez de silêncio quando os fósforos foram acessos. Infelizmente, as restrições da escola nos impediram de surpreender mais os alunos, como, por exemplo, com o "almoço romano" que havíamos planejado (que não chegamos a mencionar para a escola).

Foto 9: atividade sobre Reinos Africanos, trabalhando religião e habitações a partir do fogo.

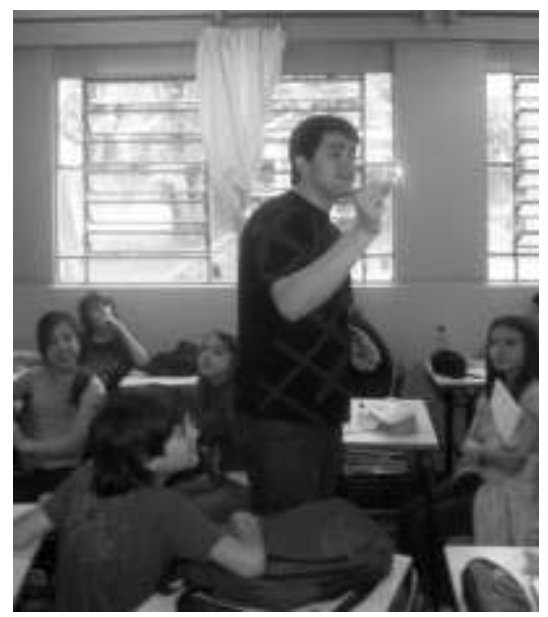


Por fim, é fundamental mencionar que, ao mesmo tempo em que as crianças aprenderam ou compreenderam várias coisas a partir de nossas intervenções, nós também aprendemos muitas coisas com elas. Além de conhecimentos pontuais e específicos, aprendemos que tratando as crianças com respeito, com verdadeiro interesse pelo que elas têm a dizer (reconhecendo que possui a mesma importância do que o que temos a dizer) e por sua realidade e deixando explícito que não nos consideramos superiores, mas iguais a elas, aprendendo com elas, rindo com elas, discutindo com elas, o trabalho se torna muito mais significativo para todos.

\section{Agradecimentos}

Agradecemos a todos que de alguma forma contribuíram para que a nossa proposta fosse aplicada com sucesso. Agradecemos à direção da Escola Estadual de Ensino Fundamental General Edson Figueiredo e à Prof.a Nara pela confiança e o acolhimento. Aos alunos das turmas 51 e 53 da mesma escola, agradecemos a oportunidade de conhecê-los, ouvi-los e muitas vezes nos surpreendermos, enriquecendo as nossas experiências docentes e de vida. Aos colegas Marcelo Noriega e Morgana Baldo, que estiveram conosco no planejamento, preparação e execução de cada atividade, agradecemos por toda a contribuição e companheirismo.

\section{Referências}

ABREU, M.; MATTOS, H. Em torno das "Diretrizes Curriculares nacionais para a educação das relações étnico-raciais e para o ensino de história e cultura afro-brasileira e africana": uma conversa com historiadores. Estudos Históricos. Rio de Janeiro, v. 21, n. 41, 2008, p. 5-20.

BARTHON, K. Qual a utilidade da história para crianças? Contributos do ensino de história para a cidadania. In BARCA, I. (Org.). Para uma educação histórica de qualidade. Actas das IV Jornadas Internacionais de Educação Histórica.Universidade do Minho, 2004. p. 11-22.

BURKE, Peter. O que é História Cultural?. Rio de Janeiro: Jorge Zahar Ed., 2008.

CAINELLI, M. Educação histórica: perspectivas de aprendizagem da história no ensino fundamental. Educar. Curitiba, Especial, 2006, p. 57-72. 
CORRÊA, G. C. Oficina: novos territórios em educação. In LUENGO, J. M. (Org.) Pedagogia Libertária: Experiências Hoje. São Paulo: Editora Imaginário, 2000.

ELIADE, Mi. Mito e realidade. São Paulo: Perspectiva, 2006.

ESPADA LIMA, H. A Micro-história italiana: escalas, indícios e singularidades. Rio de Janeiro: Civilização Brasileira, 2006.

ILLICH, I. Sociedade sem escolas. Petrópolis: Editora Vozes, 1973.

KI-ZERBO, J. (org.). História Geral da África. Brasília: UNESCO, Secad/MEC, UFSCar, 2010.

KORNIS, M. A. História e Cinema: um debate metodológico. Estudos Históricos. Rio de Janeiro, vol. 5, n. 10, 1992, p. 237-250.

PEREIRA, J. S. Reconhecendo ou construindo uma polaridade étnicoidentitária? Desafios do ensino de história no imediato contexto pós-Lei no 10.639. Estudos Históricos. Rio de Janeiro, v. 21, n. 41, 2008, p. 21-43.

PERRY, Marvin. Civilização Ocidental: uma história concisa. São Paulo: Martins Fontes, 2002.

SCHMIDT, M. A.; CAINELLI, M. Ensinar história. São Paulo: Scipione, 2004.

SLENES, R. Na senzala, uma flor: esperanças e recordações da família escrava, Brasil, Sudeste, século XIX. Rio de Janeiro: Nova Fronteira, 1999. 